\title{
Bow-Legs and Knock-Knees in Children - Self Resolving or Pathological Deformity
}

\author{
Shaikh Naeem-Ul-Haq, Syed Abdur Rub Abidi, Abdul Rehman Khan, Salman Adil, Imran \\ Samdani, Syed Adnan Ahmed
}

\begin{abstract}
OBJECTIVE: To identify and differentiate the self-resolving Paediatric Orthopedic conditions namely bow-legs and knock-knees from pathological conditions like metabolic bone diseases - rickets and bone dysplasias.

METHODOLOGY: This prospective descriptive, non-randomized, convenience sampling technique study was conducted in the out patient department of the Orthopedic units of the Jinnah Medical College Hospital Karachi, Dow University Hospital Ojha Campus Karachi and Fatima Hospital Baqai University Karachi from February 2012 - January 2018.

Total three hundreds children between 1-8 years of age were included with deformities comprising mainly of bowlegs and knock-knees. We included the children having nutritional deficiencies alongside former deformities, and excluded children with neurological disturbances or other syndromes. A detailed history of each patient was taken, emphasizing their perinatal history and developmental milestones.

RESULTS: Out of 300 patients $224(74.67 \%)$ had improvement in deformity of legs without any active treatment. There were $64(21.33 \%)$ children, who required treatment, were diagnosed as ricketic patients. There were another group of $12(4 \%)$ children who didn't show improvement without active intervention. They were categorized as suffering from epiphyseal dysplasias or post-traumatic epiphyseal injury.

CONCLUSION: The majority of deformities like bowlegs and knock-knees in children are self-resolving and are considered as physiological variant of musculoskeletal development.The knowledge of spontaneous resolution saves both the time and money spent unnecessarily on these normal variants.
\end{abstract}

KEY WORDS: Bow-legs, Knock-knees, Self-resolving deformity.

This article may be cited as: Naeem-Ul-Haq S, Abidi SAR, Khan AR, Adil S, Samdani I, Ahmed SA. Bow-Legs and Knock-Knees in Children - Self Resolving or Pathological Deformity. J Liaquat Uni Med Health Sci. 2019;18(03):197-200. doi: 10.22442/jlumhs.191830627

\section{INTRODUCTION}

Some skeletal deformities like bow-legs and knock-knees are part of the children's normal musculoskeletal development. However some pathological entities like metabolic affections such as rickets and dysplasias may present in a similar pattern. A large proportion of these bowlegs and knock-knees are innocuous, which eventually resolve spontaneously ${ }^{1}$. These abnormalities, however, pose a source of great concern and anxiety among the parents and motivate them to seek medical advice ${ }^{2}$. Molony D $2006^{3}$ reported fifty percent of all referrals to their paediatric orthopaedic clinic, who were children with normal variants of normal limb development. It is about these borderline musculoskeletal abnormalities which fall in grey zone that the clinician has to assess which patient needs treatment, since the natural history of such disorders is spontaneous resolution as the child grows.

A thorough history and examination are usually all that is required to distinguish between these normal variants and pathological conditions. The important aspects of the history that should be looked into are birth history, developmental milestone and family history $^{4,5}$. Patient should be clinically examined as a whole, including observation of gait ${ }^{6}$; as some features suggest pathological conditions and not a normal developmental variant ${ }^{7}$ :

- Abnormal facies

- Abnormal heights

- Asymmetrical limbs

- Joint movements limitations

- Leg length discrepancy

A thorough neurological examination should be done for diagnosing neuromuscular disorders ${ }^{8}$. Further investigations including radiological and hematological tests are also done for diagnosing pathological conditions. According to a study, physiological musculoskeletal complaints represented up to $22.5 \%{ }^{9}$ of pediatric orthopedic referrals and cause substantial unnecessary cost to the health system. 


\section{METHODOLOGY}

This prospective descriptive, non-randomized, convenience sampling technique study was conducted in the out patient department of the orthopedic units of the Jinnah Medical College Hospital Karachi, Dow University Hospital Ojha Campus Karachi and Fatima Hospital Baqai University Karachi from February 2012 - January 2018. Total three hundreds children between 1 to 8 years of age were included with deformities comprising mainly ofbowlegs and knock-knees. We included the children having nutritional deficiencies alongside former deformities, and excluded children with neurological disturbances or other syndromes. A detailed history of each patient was taken, emphasizing their perinatal history and developmental milestones. All patients were thoroughly examined for any abnormality, and asymmetry in facies, limbs and joints. Radiograph of lower limb in standing position were taken. Metabolic bone profiles were also done. Most of these patients were followed in OPD at every 2 months.

\section{RESULTS}

The patients were grouped into three (3) categories:

Group I-Normal Developmental variants (Physiological): In this group those children with bow -legged and knocked knees were included who were otherwise normal. Their deformity was uniformly over the whole length of the tibia with bilaterally symmetrical limb. Out of 300 children in the study, 224 $(74.67 \%)$ were enrolled in this group, who were the normal variants. 176 of the normal variants had bowlegs and 48 had knock-knees, in which $150(50 \%)$ bowlegs and $33(13 \%)$ knock-knees presented before the age of 2 (Table I).

\begin{tabular}{|l|c|c|c|}
\hline \multicolumn{4}{|c|}{ GROUP-I } \\
\hline Deformity & Male & Female & Aggregates \\
\hline Bow-legs & 124 & 52 & 176 \\
\hline Knock-knees & 36 & 12 & 48 \\
\hline & 160 & 64 & 224 \\
\hline
\end{tabular}

During follow-up visits these children showed marked improvement in the shape of their legs without any active treatment by the age of 3 years in cases of bowing and by the age of 4 in cases of genu valgum. The bowing or knocking of knees eventually straightened and children were seen walking almost straight by the age of 6 years.

Group II- Metabolic Bone Affections (Rickets): In this group those children with bow-legged and knocked knees were included who presented in asymmetrical fashion, widened ankle and wrist on radiographs. In this group children usually had constitutional symptoms i.e. irritability and poor general health. After investigations (metabolic bone profile), they were diagnosed as metabolic bone affections-rickets. Out of 300 children in the study, 64 $(21.33 \%)$ were enrolled in this group. These children promptly responded to supplemental therapy- Calcium and Vitamin Din 6 months. These deformities took 2 to 3 years to improve in appearance (Table II).

\begin{tabular}{|l|c|c|c|}
\hline \multicolumn{4}{|c|}{ GROUP-II } \\
\hline \multicolumn{1}{|c|}{ Deformity } & Male & Female & Aggregates \\
\hline Bow-legs & 24 & 14 & 38 \\
\hline Knock-knees & 16 & 10 & 26 \\
\hline & 40 & 24 & 64 \\
\hline
\end{tabular}

Group III - Epiphyseal Affections (Epiphyseal Injury or Dysplasias): The third group comprised of post-traumatic epiphyseal injury and epiphyseal dysplasias cases.This group had $12(4 \%)$ children with bowing or knocking legs with history of injury to epiphysis. Some of the children in this group showed epiphyseal growth disturbances in knees and/or other joints as well. They were labelled as epiphyseal-dysplasias (Table III).

\begin{tabular}{|l|c|c|c|}
\hline \multicolumn{4}{|c|}{ GROUP-III } \\
\hline \multicolumn{1}{|c|}{ Deformity } & Male & Female & Aggregates \\
\hline Epiphyseal Dysplasias & 3 & 1 & 4 \\
\hline Epiphyseal Injury & 6 & 2 & 8 \\
\hline & 9 & 3 & 12 \\
\hline
\end{tabular}

These children didn't show any improvement without intervention. They required active intervention in terms of braces and corrective osteotomy planned at later stage. There were 25 patients who were lost during follow up, so we excluded them.

\section{DISCUSSION}

Some musculoskeletal deformities like bow legs and knock knees are common source of parental concern in our society ${ }^{10}$. These deformities are one of the commonest unnecessary referrals to orthopedic surgeons ${ }^{11,12}$. This emphasizes the importance of recognizing the developmental norms in children to avoid unnecessary referral and expensive treatment ${ }^{13}$. The exact etiologies of these deformities are unclear and because most cases resolve with time, these deformities are often described as normal physiological variants. Genu varum (bow-leg) is seen from birth to 2 years; and genu valgum (knock-knee) is presented between 2 to 4 years ${ }^{14}$. The spontaneous correction of bow legs and knock knees in growing children were also noted by Vankka and Salenius ${ }^{15}$. Their results 
showed that pediatric knee alignment is initially $10^{\circ}$ to $15^{\circ}$ of varus (bow-leg) at birth, and reaches a neutral alignment by approximately 2 years of age.

Bow-legs are common up to 2 years of age and gradually progress to knock-knees from 2 years onwards. Other studies also confirmed the spontaneous resolution of deformities in these children $^{16,17}$. A lot of other studies have shown physiologic bow legs in 1.5 years to 2 years olds ${ }^{18-22}$. Bowing which requires further evaluation includes delayed milestone, asymmetrical (unilateral), and evidence of endocrine or neuromuscular abnormalities. Interventions like bracing or surgical procedure may be indicated in this small percentage of patients. Genu-valgum (knock-knees) is also a common finding in patients between the age of 3 and 6 years. Vankka E $1982^{15}$ noted that maximum genu valgum during the normal development was $12^{0}$ to $13^{0}$ approximately. These children should be evaluated as for any other musculoskeletal deformity. In most patients with genu-valgum no intervention are required. Further work up is required for those patients who have severe deformities or if the patient is older than 7 to 8 years of age.

\section{CONCLUSION}

The understanding of the natural history of musculoskeletal development of the lower limb is beneficial in differentiating between transitional orthopaedic deformities and pathological affections like metabolic bone diseases and epiphyseal dysplasias. Most angular deformities resolve spontaneously with passage of time and require no active treatment.

Reassurance of the family is the only treatment indicated in most of the cases. The knowledge of spontaneous resolution saves both the time and money spent unnecessarily on these normal variants. On the contrary, a high index of suspicion is required to identify the pathological conditions such as rickets and epiphyseal dysplasias, which require active interventions.

Ethical permission: Dow University of Health Sciences, letter No. DUHS/Reg/(ESTT)/2019/4585. Dated: 30-04-2019.

Conflict of Interest: There was no any conflict of interest.

Funding: There was no any funding agency.

\section{REFERENCES}

1. Joseph B. Acquired deformities of the knee. Paediatric Orthopaedic Diagnosis. 2015; 187-206. doi: 10.1007/978-81-322-2392-4_20.

2. Shaty WG. Clinical and statistical assessment of aetiological factors of genu varum in children. Thi-Qar Med J. 2015; 10(2): 23-36.

3. Molony D, Hefferman G, Dodds M, McCormack D. Normal variants in the paediatric orthopaedic population. Ir Med J. 2006; 99(1): 13-4.

4. Lincoln TL, Sued PW. Common rotational variations in children. J Am Acad Orthop Surg. 2003; 11(5): 312-20.

5. Staheli LT. Lower limb-fundamentals of pediatric orthopedics. 4th Edition. Lippincot Williams \& Wilkins, Philadelphia, 2008.

6. Frye S. Lower limb positional variations. Contemporary Pediatrics [Internet]. September 1, 2017. Available from: https://www. contemporarypediatrics.com/editors-choice-cp/7-lower-limbpositional-variations.

7. Eastwood DM, Hicks J. Paediatric orthopedicsdevelopment of the musculoskeletal system. In: O'Connell PR, Bulstrode JK, Williams NS, editors. Bailey and Love's short practice of surgery. $25^{\text {th }}$ ed. London: Hodder Arnold; 2008. P. 563-4.

8. Ganavi R. Bow legs and knock knees: is it physiological or pathological? Int $\mathrm{J}$ Contemp Pediatr. 2016; 3(2): 687-91. doi:10.18203/23493291.ijcp20161068.

9. Carli A, Saran N, Kruijt J, Alam N, Hamdy R. Physiological referrals for Paediatric musculoskeletal complaints: A costly problem that needs to be addressed. Paediatr Child Health. 2012; 17 (9): e93-7.

10. Yeo A, James K, Ramchandran M. Normal lower limb Variants in children. BMJ. 2015; 351: h3394. doi: http//doi.org/10.1136/bmj.h3394.

11. Hsu EY, Schwend RM, Julia L. How many referrals to pediatric orthopedic hospital specialty clinic are primary care problems?.J Pediatr Orthop. 2012; 32(7): 732-6. doi:10.1097/BPO.0 b013e3182699 4a4.

12. Moraleda L, Castellote M. Paediatric orthopaedic outpatient clinic referral patterns. An Pediatr (Barc). 2015; 83(2): 89-93. doi: 10.1016/j.anpedi. 2014.10.023.

13. Dobbe AM, Gibbons PJ. Common paediatric conditions of the lower limb. 2017; 53(11): 10771085. doi: 10.1111/jpc.13756.

14. Greene WB. Genu varum and genu valgum in children: differential diagnosis and guidelines for evaluation. Compr Ther. 1996; 22(1): 22-9.

15. Vankka E, Salenius P. Spontaneous correction of severe tibiofemoral deformity in growing children. Acta Orthop Scand. 1982; 53(4): 567-70.

16. Arazi M, Ogun TC, Memik R. Normal development of the tibiofemoral angle in children: a clinical study of 590 normal subjects for 3 to 17 years of age. J Pediatr Orthop. 2001; 21(2): 264-7. 
17. Paterson M. Normal variants and self limiting conditions. Paediatric Orthopaedic in Clinical Practice. 2016; 1-10.

18. Mathew SE, Madhuri V. Clinical tibiofemoral angle in south indian children. Bone Joint Res. 2013; 2 (8): 155-61.

19. Yoo JH, Choi IH, Cho TJ, Yoo WJ. Development of tibiofemoral angle in Korean children. J Korean Med Sci. 2008; 23(4): 714-7. doi: 10.3346/jkms.2008.23.4.714.

20. Rahman SA, Badahdah WA. Normal development of the tibiofemoral angle in Saudi children from 2 to 12 years of age. World Appl Sci J. 2011; 12(8): 1353-61.

21. Saini UC, Bali K, Seth B, Gahlot N, Gahlot A. Normal development of the knee angle in healthy Indian children: a clinical study of 215 children. J Child Orthop. 2010; 4(6): 579-86. doi: 10.1007/ s11832-010-0297-z.

22. Kumar D, Patnaik G, Puri N. Study of knee angle in tribal children of Andhra Pradesh. Asian J Med Sci. 2016; 7(6): 75-81. doi: 10.3126/ajms.v7i6. 15261.

\begin{tabular}{|l|}
\hline AUTHOR AFFILIATION: \\
Dr. Shaikh Naeem-ul- Haq \\
Assistant Professor, Department of Orthopedic \\
Dow international Medical College/ \\
Dow University of Health Sciences Karachi, Sindh-Pakistan. \\
Dr. Syed Abdur Rub Abidi (Corresponding Author) \\
Assistant Professor, Department of Orthopedic \\
Jinnah Medical \& Dental College/JMCH Karachi, Sindh-Pakistan. \\
Email: syedarai@yahoo.com \\
Dr, Abdul Rehman Khan \\
Assistant Professor, Department of Orthopedic \\
Dow international Medical College/ \\
Dow University of Health Sciences Karachi, Sindh-Pakistan. \\
Dr. Salman Adil \\
Assistant Professor, Department of Orthopedic \\
Baqai University Karachi, Sindh-Pakistan. \\
Dr. Imran Samdani \\
Consultant Orthopedic Surgeon \\
Abbasi Shaheed Hospital Karachi, Sindh-Pakistan. \\
Dr. Syed Adnan Ahmed \\
Consultant Orthopedic Surgeon \\
TO Clinic Karachi, Sindh-Pakistan.
\end{tabular}

